\title{
Risk factors for internal anal sphincter dysfunction in Japanese adults
}

\author{
Tatsuya Abe $^{1 *}$, Toru Kono ${ }^{2,3}$, Yoshikazu Hachiro ${ }^{1}$, Masao Kunimoto ${ }^{1}$, Hiroyuki Furukawa ${ }^{2}$ \\ ${ }^{1}$ Department of Proctology, Kunimoto Hospital, Asahikawa, Japan \\ ${ }^{2}$ Division of Gastroenterologic and General Surgery, Department of Surgery, Asahikawa Medical University, Asahikawa, Japan \\ ${ }^{3}$ Advanced Surgery Center, Sapporo Higashi Tokushukai Hospital, Sapporo, Japan \\ Email: ${ }^{t}$ t-abe@cf6.so-net.ne.jp
}

Received 13 December 2012; revised 13 January 2013; accepted 20 January 2013

\section{ABSTRACT}

Purpose: The internal anal sphincter provides most of the resting anal tone and is the main muscle responseble for continence. This study was designed to estimate the prevalence of, and identify risk factors associated with, internal anal sphincter dysfunction in Japanese adults. Methods: Anorectal manometry was performed in 1193 women and 1124 men aged 20 years or older. The maximal resting pressure, measured by a rapid pull-through technique, was defined as the highest resting pressure recorded. Internal anal sphincter dysfunction was defined as a maximal resting pressure less than $30 \mathrm{mmHg}$. Potential risk factors were assessed through self-reports, interviews, physical examinations, and medical record reviews. Multivariate logistic regression analysis was used to identify independent risk factors for internal anal sphincter dysfunction. Results: Significant differences in maximal resting pressure were seen between women $(58.1 \pm 24.9 \mathrm{mmHg})$ and men $(68.8 \pm 23.5 \mathrm{mmHg}, \mathrm{P}<$ 0.001). Maximal resting pressure decreased significantly with increasing age in both sexes. The prevalence of internal anal sphincter dysfunction was $10.4 \%$ (15.5\% in women, $5.1 \%$ in men). In a multivariate logistic regression model, age, mental disease, pelvic organ prolapse repair, and fecal incontinence were independently associated with a greater risk of internal anal sphincter dysfunction in women and men. Conclusions: Internal anal sphincter dysfunction is a common problem for women and men. Several of the identified risk factors are preventable or modifiable, and may direct future research in fecal incontinence therapy.

Keywords: Fecal Incontinence; Internal Anal Sphincter; Anorectal Manometry; Maximal Resting Pressure

${ }^{*}$ Corresponding author.

\section{INTRODUCTION}

Fecal incontinence (FI) is a common disorder with a significant impact on quality of life. The prevalence of FI in the general population increases with age in both women and men [1]. Although the cause of FI is often multifactorial, FI is frequently caused by anal sphincter insufficiency [2]. The anal sphincter consist of the circular internal (IAS) and external (EAS) anal sphincter muscles together with the sling-shaped puborectalis muscle. Although both sphincter muscles are important for the maintenance of continence, the IAS, composed of smooth muscle arranged in oblique bundles, provides most of the resting anal tone and is the main muscle responsible for preventing fecal leakage. The IAS contributes an estimated $55 \%-85 \%$ to maximal resting pressure (MRP) $[3,4]$. Low MRP is the most important predictor of FI and correlates with the Fecal Incontinence Severity Index (FISI) [5].

Despite a number of studies on FI in western countries [6-8], there has been a paucity of research about risk factors associated with IAS dysfunction (IASD). Identifying preventable or modifiable risk factors for IASD may guide future research for the prevention or treatment of FI.

The objective of this study was to provide a comprehensive description of IASD in Japanese adults and to describe demographic and other risk factors associated with IASD after multivariate adjustments.

\section{MATERIALS AND METHODS}

Between January 2006 and December 2008, 3190 consecutive subjects aged 20 years or older referred to our hospital were enrolled.

Factors potentially associated with IASD or FI were assessed by questionnaires, interviews, medical record reviews, and physical examinations. Participants filled in a structured questionnaire, which included questions about demographic characteristics (age, sex, body mass 
index (BMI), employment), stool consistency, bowel movements, presence of selected medical conditions, previous anorectal surgeries, previous cholecystectomy, current habits, laxative use, FI, and parity in women. All medical conditions and medication use were determined according to self-reports as well as in-person interviews during which written responses were clarified. Patient weight and height were measured, and BMI was categorized according to the classification proposed for Japanese adults. The validated Bristol Stool Scale was used to describe the participant's usual stool consistency [9]. This scale consists of 7 types of stool and includes pictures of each stool type to aid participants in classifying their stools. We combined stool type 1 and 2 (hard and lumpy), 3 - 5 (normal consistencies), and 6 and 7 (mushy and watery). Smoking status was categorized as nonsmoker and current smoker ( $\geq 1$ cigarettes per day). Alcohol intake was categorized as nondrinker and current drinker (more than once a week). For this study, FI was defined as any involuntary loss of mucus, liquid, or solid stool during the last 30 days; this definition of FI did not include gas.

Anorectal manometry (ARM) was performed by a single experienced examiner using a $5 \mathrm{~mm}$ diameter, 1channel solid-state catheter with a microtipped transducer ARM system (P-31, Star Medical Co., Tokyo, Japan). All subjects were examined in the left lateral position with the hips flexed to $90^{\circ}$. The lubricated catheter was introduced into the rectum. The MRP measured by means of a rapid pull-through technique was defined as the highest resting pressure recorded. IASD was defined as "low MRP" in cases where MRP was less than 30 $\mathrm{mmHg}[10]$.

Statistical analysis was performed using JMP version 9.0.2 (SAS Institute Inc, Cary, NC). MRP values were expressed as means \pm standard deviation. The MannWhitney $U$ test was used to analyze for sex differences in MRP, and regression analysis was used to search for associations with age. The chi-square test was used to test the association between low MRP and each risk factor individually. All risk factors found to be significantly associated with low MRP in univariate analyses were combined into separate multivariate logistic models for women and men. Adjusted odds ratios (OR) and 95\% confidence intervals (CI) were used to describe associations between risk factors and low MRP in univariate analyses and in multivariate analyses. $\mathrm{P}$ values $<0.05$ were considered to indicate statistical significance for all analyses.

This study was a retrospective review of existing clinical data prospectively collected on a hospital anal physiology unit computer database. This study was approved by the research and ethics committee of Kunimoto Hospital and informed consent for ARM and future use of their data was provided by all participants in the study.

\section{RESULTS}

Data from 2317 subjects (1193 women and 1124 men) who gave complete responses were analyzed. Mean age was $56.0 \pm 17.9$ years in women and $53.2 \pm 16.1$ years in men. All participants were stratified into 10-year age groups. The general characteristics of the participants are shown in Table 1. The most common medical condition was hypertension (26.8\%). FI was reported by $15.1 \%$ of women and $7.7 \%$ of men.

Significant differences in MRP were seen between women $(58.1 \pm 24.9 \mathrm{mmHg})$ and men $(68.8 \pm 23.5 \mathrm{mmHg}$; $\mathrm{P}<0.001)$. MRP decreased significantly with increasing age in both sexes (Figure 1).

The prevalence of low MRP was $10.4 \%(15.5 \%$ in women, $5.1 \%$ in men). Among women, prevalence increased from $1.7 \%$ for $20-29$ year-olds up to $52.4 \%$ for 80 years or older. For women and men combined, the most common medical conditions associated with low MRP were cognitive impairment and pelvic organ prolapse repair (Tables 2 and $\mathbf{3}$ ).

In univariate analyses, variables associated with low MRP in women and men were age, employment status, hypertension, stroke, cognitive impairment, mental disease, ischemic heart disease, any history of cancer, pelvic organ prolapse repair, laxative use, and FI. In addition, parity, dyslipidemia, spinal cord injury, anal fistula surgery, and hysterectomy were associated with low MRP in women but not in men, while BMI, usual stool consistency, diabetes mellitus, hemorrhoidectomy, and rectal surgery were associated with low MRP in men alone.

In a multivariate logistic regression model, age, men tal disease, pelvic organ prolapse repair, and FI were independently associated with a greater risk of low MRP in women and men. In addition, ischemic heart disease was associated with low MRP in women alone. By contrast, smoking or alcohol intake and diabetes mellitus were significantly negative associated with low MRP in women (Tables 4 and 5).

\section{DISCUSSION}

The present study investigated the influence of age, sex, and other possible risk factors for low MRP in a large number of Japanese adults spanning a wide age range. The main results are the following: 1) women had significantly lower MRP than men; 2) MRP decreased with increasing age in both sexes; 3 ) independent risk factors for low MRP in both sexes include advancing age, FI, mental disease, and pelvic organ prolapse repair.

FI is defined as either the involuntary passage of or the inability to control the discharge of fecal matter through 
Table 1. General characteristics of study subjects.

\begin{tabular}{|c|c|c|c|c|c|c|c|}
\hline \multicolumn{2}{|c|}{ Characteristic } & \multicolumn{2}{|c|}{$\begin{array}{c}\text { Overall } \\
n=2317\end{array}$} & \multicolumn{2}{|c|}{$\begin{array}{c}\text { Women } \\
\mathbf{n}=1193\end{array}$} & \multicolumn{2}{|c|}{$\begin{array}{c}\text { Men } \\
\mathrm{n}=1124\end{array}$} \\
\hline Age (year) & $20-29$ & 201 & (8.7) & 117 & $(9.8)$ & 84 & $(7.5)$ \\
\hline & $30-39$ & 348 & $(15.0)$ & 149 & $(12.5)$ & 199 & (17.7) \\
\hline & $40-49$ & 339 & $(14.6)$ & 157 & $(13.2)$ & 182 & $(16.2)$ \\
\hline & $50-59$ & 470 & $(20.3)$ & 216 & $(18.1)$ & 254 & (22.6) \\
\hline & $60-69$ & 421 & $(18.2)$ & 231 & (19.4) & 190 & (16.9) \\
\hline & $70-79$ & 391 & (16.9) & 220 & $(18.4)$ & 171 & $(15.2)$ \\
\hline & $\geq 80$ & 147 & $(6.3)$ & 103 & $(8.6)$ & 44 & (3.9) \\
\hline \multirow[t]{3}{*}{ BMI } & Underweight $(<18.5)$ & 140 & $(6.0)$ & 87 & (7.3) & 53 & $(4.7)$ \\
\hline & Normal (18.5 - 24.9) & 1628 & $(70.3)$ & 898 & $(75.3)$ & 730 & (64.9) \\
\hline & Overweight ( $\geq 25$ ) & 549 & $(23.7)$ & 208 & $(17.4)$ & 341 & $(30.3)$ \\
\hline Parity & At least one vaginal & & & 924 & (77.4) & & \\
\hline \multirow[t]{2}{*}{ Employment status } & Employed/student & 1281 & $(55.3)$ & 470 & $(39.4)$ & 811 & $(72.2)$ \\
\hline & Unemployed/other & 1036 & $(44.7)$ & 723 & $(60.6)$ & 313 & $(27.8)$ \\
\hline \multirow[t]{4}{*}{ Usual stool consistency } & Normal stools & 1403 & $(60.6)$ & 635 & $(53.2)$ & 768 & $(68.3)$ \\
\hline & Hard, lumpy stools & 688 & $(29.7)$ & 466 & $(39.1)$ & 222 & $(19.8)$ \\
\hline & Loose, watery stools & 150 & $(6.5)$ & 47 & (3.9) & 103 & $(9.2)$ \\
\hline & Other & 76 & (3.3) & 45 & $(3.8)$ & 31 & $(2.8)$ \\
\hline \multirow[t]{3}{*}{ Frequency of bowel movements } & $>21 \mathrm{BM} /$ week & 113 & (4.9) & 49 & $(4.1)$ & 64 & $(5.7)$ \\
\hline & 3 - $21 \mathrm{BM} /$ week & 2001 & $(86.4)$ & 1001 & $(83.9)$ & 1000 & $(89.0)$ \\
\hline & $<3 \mathrm{BM} /$ week & 203 & $(8.8)$ & 143 & $(12.0)$ & 60 & $(5.3)$ \\
\hline \multirow[t]{10}{*}{ Comorbid conditions } & Hypertension & 620 & $(26.8)$ & 317 & $(26.6)$ & 303 & $(27.0)$ \\
\hline & Diabetes mellitus & 155 & $(6.7)$ & 75 & $(6.3)$ & 80 & $(7.1)$ \\
\hline & Dyslipidemia & 257 & $(11.1)$ & 154 & (12.9) & 103 & $(9.2)$ \\
\hline & Stroke & 93 & $(4.0)$ & 44 & (3.7) & 49 & $(4.4)$ \\
\hline & Cognitive impairment & 29 & $(1.3)$ & 17 & $(1.4)$ & 12 & $(1.1)$ \\
\hline & Mental disease & 102 & (4.4) & 60 & (5.0) & 42 & $(3.7)$ \\
\hline & Ischemic heart disease & 64 & (2.9) & 27 & $(2.3)$ & 37 & $(3.3)$ \\
\hline & Any history of cancer & 108 & $(4.7)$ & 58 & $(4.9)$ & 50 & $(4.4)$ \\
\hline & Bronchial asthma & 98 & $(4.2)$ & 57 & $(4.8)$ & 41 & $(3.6)$ \\
\hline & Spinal cord injury & 46 & $(2.0)$ & 22 & $(1.8)$ & 24 & $(2.1)$ \\
\hline \multirow[t]{7}{*}{ Previous surgeries } & Hemorrhoidectomy & 314 & $(13.6)$ & 156 & $(13.1)$ & 158 & (14.1) \\
\hline & Anal fissure surgery & 28 & $(1.2)$ & 16 & $(1.3)$ & 12 & $(1.1)$ \\
\hline & Anal fistula surgery & 82 & $(3.5)$ & 16 & $(1.3)$ & 66 & $(5.9)$ \\
\hline & Hysterectomy & & & 97 & $(8.1)$ & & \\
\hline & Pelvic organ prolapse repair & 51 & $(2.2)$ & 43 & (3.6) & 8 & $(0.7)$ \\
\hline & Rectal surgery & 16 & $(0.7)$ & 7 & $(0.6)$ & 9 & $(0.8)$ \\
\hline & Cholecystectomy & 43 & (1.9) & 17 & $(1.4)$ & 26 & $(2.3)$ \\
\hline \multirow[t]{2}{*}{ Current habits } & Smoking & 572 & $(24.7)$ & 194 & $(16.3)$ & 378 & (33.6) \\
\hline & Alcohol intake & 979 & $(42.3)$ & 293 & $(24.6)$ & 686 & (61.0) \\
\hline Laxative use & & 471 & $(20.3)$ & 347 & $(29.1)$ & 124 & (11.0) \\
\hline Fecal incontinence & & 266 & $(11.5)$ & 180 & $(15.1)$ & 86 & (7.7) \\
\hline
\end{tabular}

$\mathrm{BMI}=$ body mass index. $\mathrm{BM}=$ bowel movements. Data are numbers of subjects with percentages in parentheses. Percentages may not sum to 100 because of rounding. 


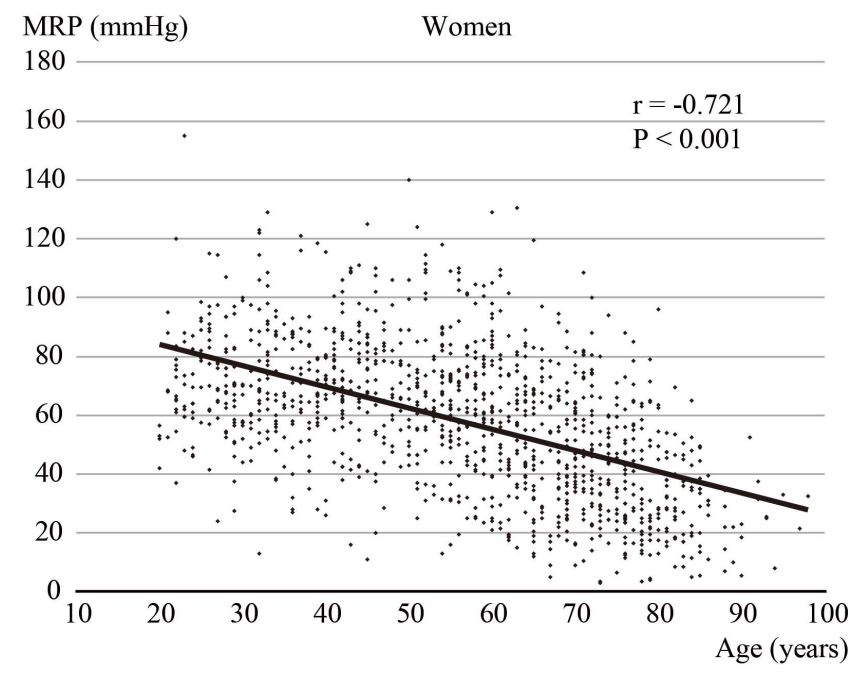

(a)

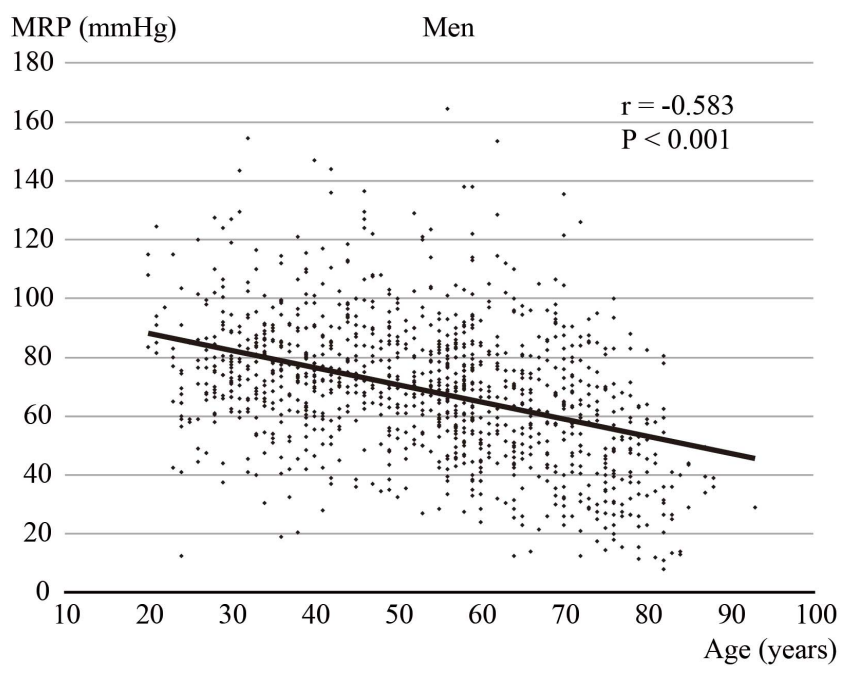

(b)

Figure 1. Regression analysis on the influence of age on maximal resting pressure (MRP) in women (a) and men (b). MRP decreased significantly with increasing age in both sexes (women, $\mathrm{r}=-0.721, \mathrm{P}<0.001 ; \mathrm{men}, \mathrm{r}=-0.583, \mathrm{P}<0.001$ ).

the anal canal [1]. Clinically there are 3 subtypes: 1) passive incontinence - the involuntary discharge of rectal contents without awareness; 2) urge incontinence-the discharge of stool in spite of active attempts to retain bowel contents; and 3) combined incontinence-both passive and urge incontinence [2]. The majority of FI patients have passive incontinence [11]. Passive incontinence is generally associated with dysfunction of the smooth muscle of the IAS, whereas urge incontinence is related to dysfunction of the striated muscle of the EAS $[1,2]$. At rest, the IAS is in a tonically contracted state, and is innervated by the autonomic nervous system. The IAS plays a key role in maintaining continence, providing $55 \%-85 \%$ of MRP $[3,4]$.

Several studies have investigated the effect of sex on resting pressure of the anal canal [12-15]. The data are contradictory, with about half of the studies reporting comparable resting pressures in women and men, and the other half citing lower resting pressure in women. In most of these studies, the number of male and female subjects was rather low. Laurberg and Swash [12], who studied a larger cohort of subjects (102 women and 19 men), observed a significantly lower resting pressure in women. This is in accordance with the results of our study on more than 1000 people of both sexes.

Reports on the effects of aging on MRP are also conflicting. Some studies observed a significant lowering of MRP with age (more often in women than in men), while others found only a small decrease in MRP that did not reach statistical significance. Other studies did not see a decreased MRP in their older subjects [12-15]. In addition to the aforementioned problem of small sample size, most studies included patients of varying ages and grouped them differently. In the present study, we divided the subjects into 7 age groups by decade, and used regression analysis to search for effects of age on MRP, and found that MRP significantly decreases with age in women as well as in men. This age-dependent decrease in MRP is thought to be due to fibrosis of the IAS in elderly patients $[16,17]$.

Studies examining independent risk factors for FI have implicated age, obstetric and gynecologic factors, several medical conditions, and poor health. In particular, age, parity, vaginal delivery, diabetes, diarrhea, and neurologic conditions have notably been associated $[6-8,18,19]$.

This study has several limitations that should be considered when interpreting the results. First, prevalence estimates were limited to non-institutionalized individuals, and because the prevalence of FI in the nursing home population is higher than in the community $[1,2]$, the overall prevalence of IASD is likely underestimated, especially among older participants. Second, as in previous large epidemiological studies, comorbid conditions were determined according to self-reports instead of through clinician-derived methods.

Since women were found to have a higher prevalence of FI than men, in some prior studies, it was hypothesized that this sex difference is due to obstetrical injuries being a major risk factor for FI [18,19]. In this survey of the entire adult lifespan, there was a significant difference in the prevalence of low MRP between women and men. In univariate analysis, vaginal delivery was associated with a higher prevalence of low MRP in women, but this association was no longer significant after multivariate adjustment. Whitehead et al. [7] did not find a significant difference in the prevalence of FI between women and men comprising the entire adult lifespan. Other studies that included a broad range of ages have 
Table 2. Baseline characteristics of the risks for low MRP of women.

\begin{tabular}{|c|c|c|c|c|c|c|}
\hline \multicolumn{2}{|c|}{ Risk factor } & \multicolumn{2}{|c|}{$\begin{array}{c}\text { Women } \\
\mathrm{n}=1193\end{array}$} & \multicolumn{2}{|c|}{$\begin{array}{c}\text { Low MRP } \\
\mathrm{n}=185(15.5)\end{array}$} & \multirow{2}{*}{$\begin{array}{c}\mathbf{P} \\
<0.001\end{array}$} \\
\hline Age (year) & $20-29$ & 117 & $(9.8)$ & 2 & $(1.7)$ & \\
\hline & $30-39$ & 149 & $(12.5)$ & 4 & $(2.7)$ & \\
\hline & $40-49$ & 157 & $(13.2)$ & 5 & $(3.1)$ & \\
\hline & $50-59$ & 216 & $(18.1)$ & 9 & $(4.5)$ & \\
\hline & $60-69$ & 231 & $(19.4)$ & 42 & $(18.2)$ & \\
\hline & $70-79$ & 220 & $(18.4)$ & 69 & $(31.4)$ & \\
\hline & $\geq 80$ & 103 & (8.6) & 54 & $(52.4)$ & \\
\hline \multirow[t]{3}{*}{ BMI } & Underweight $(<18.5)$ & 87 & (7.3) & 20 & $(23.0)$ & 0.13 \\
\hline & Normal (18.5 - 24.9) & 898 & $(75.3)$ & 135 & $(15.0)$ & \\
\hline & Overweight $(\geq 25)$ & 208 & $(17.4)$ & 30 & $(14.4)$ & \\
\hline \multirow[t]{2}{*}{ Parity } & At least one vaginal & 924 & $(77.4)$ & 173 & $(18.7)$ & $<0.001$ \\
\hline & None & 269 & $(22.6)$ & 12 & $(4.5)$ & \\
\hline \multirow[t]{2}{*}{ Employment status } & Employed/student & 470 & (39.4) & 33 & $(7.0)$ & $<0.001$ \\
\hline & Unemployed/other & 723 & $(60.6)$ & 152 & $(21.0)$ & \\
\hline \multirow[t]{4}{*}{ Usual stool consistency } & Normal stools & 635 & $(53.2)$ & 102 & $(16.1)$ & 0.41 \\
\hline & Hard, lumpy stools & 466 & $(39.1)$ & 73 & $(15.7)$ & \\
\hline & Loose, watery stools & 47 & $(3.9)$ & 7 & (14.9) & \\
\hline & Other & 45 & $(3.8)$ & 3 & $(6.7)$ & \\
\hline \multirow[t]{3}{*}{ Frequency of bowel movements } & $>21 \mathrm{BM} /$ week & 49 & $(4.1)$ & 12 & $(24.5)$ & 0.06 \\
\hline & 3 - $21 \mathrm{BM} /$ week & 1001 & $(83.9)$ & 145 & $(14.5)$ & \\
\hline & $<3 \mathrm{BM} /$ week & 143 & $(12.0)$ & 28 & $(19.6)$ & \\
\hline \multirow[t]{10}{*}{ Comorbid conditions } & Hypertension & 317 & $(26.6)$ & 81 & $(25.6)$ & $<0.001$ \\
\hline & Diabetes mellitus & 75 & $(6.3)$ & 16 & $(21.3)$ & 0.15 \\
\hline & Dyslipidemia & 154 & $(12.9)$ & 34 & $(22.1)$ & 0.01 \\
\hline & Stroke & 44 & $(3.7)$ & 13 & $(29.6)$ & 0.009 \\
\hline & Cognitive impairment & 17 & (1.4) & 10 & $(58.8)$ & $<0.001$ \\
\hline & Mental disease & 60 & $(5.0)$ & 17 & $(28.3)$ & 0.005 \\
\hline & Ischemic heart disease & 27 & $(2.3)$ & 15 & $(55.6)$ & $<0.001$ \\
\hline & Any history of cancer & 58 & $(4.9)$ & 16 & $(27.6)$ & 0.009 \\
\hline & Bronchial asthma & 57 & $(4.8)$ & 13 & $(22.8)$ & 0.12 \\
\hline & Spinal cord injury & 22 & $(1.8)$ & 11 & $(50.0)$ & $<0.001$ \\
\hline \multirow[t]{7}{*}{ Previous surgeries } & Hemorrhoidectomy & 156 & $(13.1)$ & 29 & $(18.6)$ & 0.25 \\
\hline & Anal fissure surgery & 16 & $(1.3)$ & 4 & $(25.0)$ & 0.29 \\
\hline & Anal fistula surgery & 16 & $(1.3)$ & 6 & $(37.5)$ & 0.01 \\
\hline & Hysterectomy & 97 & $(8.1)$ & 25 & $(25.8)$ & 0.004 \\
\hline & Pelvic organ prolapse repair & 43 & (3.6) & 25 & $(58.1)$ & $<0.001$ \\
\hline & Rectal surgery & 7 & $(0.6)$ & 3 & $(42.9)$ & 0.08 \\
\hline & Cholecystectomy & 17 & $(1.4)$ & 5 & $(29.4)$ & 0.11 \\
\hline \multirow[t]{2}{*}{ Current habits } & Smoking & 194 & $(16.3)$ & 5 & $(2.6)$ & $<0.001$ \\
\hline & Alcohol intake & 293 & $(24.6)$ & 7 & $(2.4)$ & $<0.001$ \\
\hline Laxative use & & 347 & $(29.1)$ & 77 & $(22.2)$ & $<0.001$ \\
\hline Fecal incontinence & & 180 & $(15.1)$ & 103 & $(57.2)$ & $<0.001$ \\
\hline
\end{tabular}

$\mathrm{MRP}=$ maximal resting pressure. $\mathrm{BMI}=$ body mass index. $\mathrm{BM}=$ bowel movements. Data are numbers of subjects with percentages in parentheses. Percentages may not sum to 100 because of rounding. 
Table 3. Baseline characteristics of the risks for low MRP of men.

\begin{tabular}{|c|c|c|c|c|c|c|}
\hline \multicolumn{2}{|c|}{ Risk factor } & \multicolumn{2}{|c|}{$\begin{array}{c}\text { Men } \\
\mathrm{n}=1124\end{array}$} & \multicolumn{2}{|c|}{$\begin{array}{c}\text { Low MRP } \\
\mathrm{n}=57(5.1)\end{array}$} & \multirow{2}{*}{$\begin{array}{c}\mathbf{P} \\
<0.001\end{array}$} \\
\hline Age (year) & $20-29$ & 84 & $(7.5)$ & 1 & $(1.2)$ & \\
\hline & $30-39$ & 199 & $(17.7)$ & 2 & $(1.0)$ & \\
\hline & $40-49$ & 182 & $(16.2)$ & 1 & $(0.6)$ & \\
\hline & $50-59$ & 254 & $(22.6)$ & 3 & $(1.2)$ & \\
\hline & $60-69$ & 190 & $(16.9)$ & 11 & $(5.8)$ & \\
\hline & $70-79$ & 171 & $(15.2)$ & 26 & $(15.2)$ & \\
\hline & $\geq 80$ & 44 & (3.9) & 13 & $(29.5)$ & \\
\hline \multirow[t]{3}{*}{ BMI } & Underweight $(<18.5)$ & 53 & $(4.7)$ & 5 & $(9.4)$ & 0.01 \\
\hline & Normal (18.5 - 24.9) & 730 & $(64.9)$ & 44 & $(6.0)$ & \\
\hline & Overweight ( $\geq 25$ ) & 341 & $(30.3)$ & 8 & $(2.3)$ & \\
\hline \multirow[t]{2}{*}{ Employment status } & Employed/student & 811 & $(72.2)$ & 17 & $(2.1)$ & $<0.001$ \\
\hline & Unemployed/other & 313 & $(27.8)$ & 40 & $(12.8)$ & \\
\hline \multirow[t]{4}{*}{ Usual stool consistency } & Normal stools & 768 & $(68.3)$ & 27 & (3.5) & 0.005 \\
\hline & Hard, lumpy stools & 222 & $(19.8)$ & 20 & $(9.0)$ & \\
\hline & Loose, watery stools & 103 & $(9.2)$ & 7 & $(6.8)$ & \\
\hline & Other & 31 & $(2.8)$ & 3 & $(9.7)$ & \\
\hline \multirow[t]{3}{*}{ Frequency of bowel movements } & $>21 \mathrm{BM} /$ week & 64 & $(5.7)$ & 6 & $(9.4)$ & 0.27 \\
\hline & $3-21 \mathrm{BM} /$ week & 1000 & $(89.0)$ & 48 & $(4.8)$ & \\
\hline & $<3 \mathrm{BM} /$ week & 60 & (5.3) & 3 & $(5.0)$ & \\
\hline \multirow[t]{10}{*}{ Comorbid conditions } & Hypertension & 303 & $(27.0)$ & 25 & (8.6) & 0.003 \\
\hline & Diabetes mellitus & 80 & (7.1) & 8 & $(10.0)$ & 0.04 \\
\hline & Dyslipidemia & 103 & $(9.2)$ & 6 & $(5.8)$ & 0.71 \\
\hline & Stroke & 49 & $(4.4)$ & 6 & $(12.2)$ & 0.02 \\
\hline & Cognitive impairment & 12 & $(1.1)$ & 7 & $(58.3)$ & $<0.001$ \\
\hline & Mental disease & 42 & $(3.7)$ & 8 & $(19.1)$ & $<0.001$ \\
\hline & Ischemic heart disease & 37 & $(3.3)$ & 5 & $(13.5)$ & 0.02 \\
\hline & Any history of cancer & 50 & $(4.4)$ & 6 & $(12.0)$ & 0.02 \\
\hline & Bronchial asthma & 41 & (3.6) & 3 & (7.3) & 0.50 \\
\hline & Spinal cord injury & 24 & $(2.0)$ & 2 & $(8.3)$ & 0.46 \\
\hline \multirow[t]{6}{*}{ Previous surgeries } & Hemorrhoidectomy & 158 & $(14.1)$ & 19 & $(12.0)$ & $<0.001$ \\
\hline & Anal fissure surgery & 12 & $(1.1)$ & 1 & $(8.3)$ & 0.61 \\
\hline & Anal fistula surgery & 66 & (5.9) & 6 & $(9.1)$ & 0.13 \\
\hline & Pelvic organ prolapse repair & 8 & $(0.7)$ & 4 & $(50.0)$ & $<0.001$ \\
\hline & Rectal surgery & 9 & $(0.8)$ & 3 & $(33.3)$ & $<0.001$ \\
\hline & Cholecystectomy & 26 & $(2.3)$ & 1 & $(3.8)$ & 0.77 \\
\hline \multirow[t]{2}{*}{ Current habits } & Smoking & 378 & $(33.6)$ & 15 & $(4.0)$ & 0.37 \\
\hline & Alcohol intake & 686 & $(61.0)$ & 25 & $(3.6)$ & 0.007 \\
\hline Laxative use & & 124 & $(11.0)$ & 19 & $(15.3)$ & $<0.001$ \\
\hline Fecal incontinence & & 86 & (7.7) & 26 & $(30.2)$ & $<0.001$ \\
\hline
\end{tabular}

$\mathrm{MRP}=$ maximal resting pressure $\mathrm{BMI}=$ body mass index. $\mathrm{BM}=$ bowel movements. Data are numbers of subjects with percentages in parentheses. Percentages may not sum to 100 because of rounding. 
Table 4. Odds ratios for variables associated with low MRP of women.

\begin{tabular}{|c|c|c|c|c|c|c|}
\hline \multirow{2}{*}{$\begin{array}{c}\text { Risk factor } \\
\text { Age (10-year interval) }\end{array}$} & \multicolumn{2}{|c|}{$\begin{array}{c}\text { Univariate analysis } \\
\text { OR }(95 \% \mathrm{CI})\end{array}$} & \multirow{2}{*}{$\begin{array}{c}\mathbf{P} \\
<0.001\end{array}$} & \multicolumn{2}{|c|}{$\begin{array}{c}\text { Multivariate analysis } \\
\text { OR }(95 \% \text { CI })\end{array}$} & \multirow{2}{*}{$\begin{array}{c}\mathbf{P} \\
<0.001\end{array}$} \\
\hline & 2.34 & $(2.04,2.71)$ & & 1.74 & $(1.44,2.12)$ & \\
\hline \multicolumn{7}{|l|}{ BMI (vs. normal) } \\
\hline Underweight & 1.69 & $(0.97,2.82)$ & 0.06 & 2.05 & $(0.92,4.42)$ & 0.08 \\
\hline Overweight & 0.95 & $(0.61,1.44)$ & 0.82 & 0.70 & $(0.41,1.16)$ & 0.17 \\
\hline Parity (vs. none) & 4.93 & $(2.82,9.49)$ & $<0.001$ & 1.83 & $(0.87,4.17)$ & 0.11 \\
\hline \multicolumn{7}{|c|}{ Employment status (vs. employed/student) } \\
\hline Unemployed/other & 3.53 & $(2.40,5.32)$ & $<0.001$ & 1.49 & $(0.86,2.56)$ & 0.15 \\
\hline \multicolumn{7}{|c|}{ Usual stool consistency (vs. normal stools) } \\
\hline Hard, lumpy stools & 0.97 & $(0.70,1.34)$ & 0.86 & 0.75 & $(0.46,1,23)$ & 0.26 \\
\hline Loose, watery stools & 0.91 & $(0.37,1.98)$ & 0.83 & 0.93 & $(0.33,2.83)$ & 0.89 \\
\hline Other & 0.37 & $(0.09,1.05)$ & 0.06 & 0.81 & $(0.17,2.92)$ & 0.77 \\
\hline \multicolumn{7}{|l|}{ Comorbid condition } \\
\hline Hypertension & 2.55 & $(1.84,3.53)$ & $<0.001$ & 0.74 & $(0.46,1.16)$ & 0.19 \\
\hline Diabetes mellitus & 1.52 & $(0.85,2.71)$ & 0.15 & 0.40 & $(0.18,0.82)$ & 0.01 \\
\hline Dyslipidemia & 1.67 & $(1.10,2.53)$ & 0.01 & 1.41 & $(0.82,2.38)$ & 0.21 \\
\hline Stroke & 2.38 & $(1.22,4.64)$ & 0.009 & 0.47 & $(0.19,1.12)$ & 0.09 \\
\hline Cognitive impairment & 8.17 & $(3.07,21.8)$ & $<0.001$ & 0.83 & $(0.24,3.07)$ & 0.78 \\
\hline Mental disease & 2.27 & $(1.27,4.08)$ & 0.005 & 2.23 & $(1.00,4.84)$ & 0.049 \\
\hline Ischemic heart disease & 7.32 & $(3.37,15.9)$ & $<0.001$ & 3.14 & $(1.23,8.22)$ & 0.02 \\
\hline Any history of cancer & 2.18 & $(1.20,3.96)$ & 0.009 & 1.11 & $(0.47,2.50)$ & 0.81 \\
\hline Spinal cord injury & 5.73 & $(2.45,13.4)$ & $<0.001$ & 2.51 & $(0.82,7.58)$ & 0.10 \\
\hline \multicolumn{7}{|l|}{ Previous surgeries } \\
\hline Hemorrhoidectomy & 1.29 & $(0.83,2.00)$ & 0.25 & 0.97 & $(0.55,1.65)$ & 0.91 \\
\hline Anal fistula surgery & 3.35 & $(1.20,9.32)$ & 0.01 & 1.95 & $(0.48,7.04)$ & 0.33 \\
\hline Hysterectomy & 2.03 & $(1.25,3.30)$ & 0.004 & 1.57 & $(0.82,2.95)$ & 0.17 \\
\hline Pelvic organ prolapse repair & 8.59 & $(4.58,16.1)$ & $<0.001$ & 2.48 & $(1.07,5.84)$ & 0.03 \\
\hline Rectal surgery & 4.14 & $(0.80,18.9)$ & 0.08 & 1.11 & $(0.17,6.75)$ & 0.91 \\
\hline \multicolumn{7}{|l|}{ Current habits } \\
\hline Smoking & 0.12 & $(0.04,0.27)$ & $<0.001$ & 0.25 & $(0.10,0.56)$ & $<0.001$ \\
\hline Alcohol intake & 0.10 & $(0.04,0.20)$ & $<0.001$ & 0.27 & $(0.08,0.72)$ & 0.007 \\
\hline Laxative use & 1.95 & $(1.41,2.69)$ & $<0.001$ & 1.29 & $(0.81,2.05)$ & 0.29 \\
\hline Fecal incontinence & 15.17 & $(10.5,22.1)$ & $<0.001$ & 8.16 & $(5.20,12.9)$ & $<0.001$ \\
\hline
\end{tabular}

also failed to find a sex difference in FI prevalence or an effect of obstetrical injury $[6,8,20]$. This suggests that obstetrical injuries are not the most common cause of FI in women. Perineal tears are classified into 4 degrees. A fourth-degree tear is defined as an injury that extends through the fascia and musculature of the perineal body and involves the anal sphincter complex (EAS and IAS) and anal epithelium. Third-degree tears involve some or all of the fibers of the EAS, but do not necessarily involve the IAS. Faltin et al. [21] reported that clinically undetected tears of the anal sphincter were diagnosed by anal endosonography in 42 of 150 women (28\%). EAS injury alone was observed in 30 women $(20 \%)$, IAS injury alone in $2(1.3 \%)$, and both in $10(7 \%)$. In a study of 62 women with FI related to obstetrical procedures, anal endosonography revealed EAS defects in $90 \%$ and IAS defects in $65 \%$ of the subjects [22]. Our data also suggests that EAS injury is the predominant cause of FI after vaginal delivery.

Previous studies have found diabetes mellitus to increase the risk of FI $[8,23]$. Ward and Tunuguntla [23] reported that $4 \%$ of diabetic patients suffered from FI. 
Table 5. Odds ratios for variables associated with low MRP of men.

\begin{tabular}{|c|c|c|c|c|c|c|}
\hline \multirow{2}{*}{$\begin{array}{c}\text { Risk factor } \\
\text { Age (10-year interval) }\end{array}$} & \multicolumn{2}{|c|}{$\begin{array}{l}\text { Univariate analysis } \\
\text { OR }(95 \% \mathrm{CI})\end{array}$} & \multirow{2}{*}{$\begin{array}{c}\mathbf{P} \\
<0.001\end{array}$} & \multicolumn{2}{|c|}{$\begin{array}{c}\text { Multivariate analysis } \\
\text { OR }(95 \% \text { CI })\end{array}$} & \multirow{2}{*}{$\begin{array}{c}\mathbf{P} \\
<0.001\end{array}$} \\
\hline & 2.54 & $(2.02,3.29)$ & & 2.36 & $(1.68,3.41)$ & \\
\hline \multicolumn{7}{|l|}{ BMI (vs. Normal) } \\
\hline Underweight & 1.62 & $(0.54,3.94)$ & 0.35 & 1.15 & $(0.36,4.55)$ & 0.82 \\
\hline Overweight & 0.37 & $(0.16,0.76)$ & 0.006 & 0.49 & $(0.19,1.13)$ & 0.10 \\
\hline \multicolumn{7}{|c|}{ Employment status (vs. Employed/student) } \\
\hline Unemployed/Other & 6.84 & $(3.88,12.6)$ & $<0.001$ & 1.10 & $(0.48,2.49)$ & 0.81 \\
\hline \multicolumn{7}{|c|}{ Usual stool consistency (vs. normal stools) } \\
\hline Hard, lumpy stools & 2.72 & $(1.48,4.93)$ & 0.002 & 1.94 & $(0.59,5.68)$ & 0.27 \\
\hline Loose, watery stools & 2.00 & $(0.79,4.48)$ & 0.14 & 1.57 & $(0.68,3.52)$ & 0.29 \\
\hline Other & 2.94 & $(0.67,8.99)$ & 0.13 & 2.30 & $(0.37,10.3)$ & 0.85 \\
\hline \multicolumn{7}{|l|}{ Comorbid condition } \\
\hline Hypertension & 2.22 & $(1.29,3.81)$ & 0.003 & 0.67 & $(0.31,1.41)$ & 0.30 \\
\hline Diabetes mellitus & 2.26 & $(1.03,4.95)$ & 0.04 & 0.97 & $(0.33,2.53)$ & 0.96 \\
\hline Dyslipidemia & 1.18 & $(0.49,2.81)$ & 0.71 & 0.86 & $(0.27,2.29)$ & 0.78 \\
\hline Stroke & 2.80 & $(1.14,6.89)$ & 0.02 & 0.48 & $(0.13,1.47)$ & 0.21 \\
\hline Cognitive impairment & 29.73 & $(9.11,98.0)$ & $<0.001$ & 4.37 & $(0.97,21.5)$ & 0.06 \\
\hline Mental disease & 4.96 & $(2.18,11.3)$ & $<0.001$ & 7.29 & $(2.36,21.2)$ & $<0.001$ \\
\hline Ischemic heart disease & 3.11 & $(1.16,8.31)$ & 0.02 & 1.98 & $(0.53,6.32)$ & 0.29 \\
\hline Any history of cancer & 2.74 & $(1.11,6.72)$ & 0.02 & 0.62 & $(0.16,1.98)$ & 0.44 \\
\hline Spinal cord injury & 1.73 & $(0.40,7.53)$ & 0.46 & 1.40 & $(0.19,5.98)$ & 0.70 \\
\hline \multicolumn{7}{|l|}{ Previous surgeries } \\
\hline Hemorrhoidectomy & 3.34 & $(1.87,5.96)$ & $<0.001$ & 1.55 & $(0.72,3.21)$ & 0.26 \\
\hline Anal fistula surgery & 1.97 & $(0.81,4.78)$ & 0.13 & 2.02 & $(0.57,6.02)$ & 0.26 \\
\hline Pelvic organ prolapse repair & 20.06 & $(4.88,82.4)$ & $<0.001$ & 11.87 & $(1.71,88.9)$ & 0.01 \\
\hline Rectal surgery & 9.82 & $(2.39,40.3)$ & $<0.001$ & 5.94 & $(0.76,43.9)$ & 0.09 \\
\hline \multicolumn{7}{|l|}{ Current habits } \\
\hline Smoking & 0.69 & $(0.37,1.24)$ & 0.37 & 0.79 & $(0.65,2.42)$ & 0.50 \\
\hline Alcohol intake & 0.47 & $(0.28,0.82)$ & 0.007 & 1.15 & $(0.53,2.40)$ & 0.72 \\
\hline Laxative use & 4.58 & $(2.55,8.23)$ & $<0.001$ & 1.57 & $(0.68,3.51)$ & 0.28 \\
\hline Fecal incontinence & 14.08 & $(7.83,25.23)$ & $<0.001$ & 5.13 & $(2.14,12.12)$ & 0.001 \\
\hline
\end{tabular}

$\mathrm{MRP}=$ maximal resting pressure. $\mathrm{OR}=$ odds ratio. $\mathrm{CI}=$ confidence interval. $\mathrm{BMI}=$ body mass index. Only variables found to be significant in univariate analyses for women or men were included in the multivariate regressions and shown in the table. Multivariate odds ratios are adjusted for all other risk factors in the table.

The underlying pathophysiology of anorectal dysfunction in diabetic patients with FI is not well understood. Diabetes mellitus may contribute to FI through sphincter or pelvic floor weakness from anatomic defects, nerve damage, or microvascular complications. Schiller et al. [24] found IASD secondary to autonomic neuropathy responsible for FI in 16 diabetic patients. In contrast, Rogers [25] reported that EAS dysfunction might play an important role. Other reports suggested that both IAS and EAS dysfunction might be involved [26,27]. In the present study, the univariate association between diabetes mellitus and low MRP was significant for men, but after multivariate adjustment, this relationship did not hold. On the contrary, in women low MRP was significantly negatively associated with diabetes mellitus after multivariate adjustment. The lumbar sympathetic innervation inhibits the colon and provides motor stimulation to the IAS. The pudendal nerves, on the other hand, are somatic nerves that innervate the EAS. Diabetic pudendal neuropathy leads to delay of pudendal nerve terminal motor latency, causes EAS damage, and may result in FI [28]. Our results suggest that somatic neuropathy plays a more important role in FI in diabetic patients.

FI was significantly associated with low MRP after 
multivariate adjustment in both sexes. More treatment options for FI makes a proper pretreatment evaluation increasingly important, whether by means of subjective severity questionnaires, such as the FISI, or by objective measurements, such as ARM, anal endosonography, electromyography, and defecography [1]. Bordeianou et al. [5] reported MRP was the only objective measurement that seems to correlate with both FISI and the presence of sphincteric defects on anal endosonography, while maximal squeeze pressure (MSP) generated by the EAS was not correlated. Our results confirm a strong association between low MRP and FI.

Mental disease was found to be independently associated with low MRP. The IAS has spontaneous myogenic tone, but it also receives inputs from the sympathetic and parasympathetic nervous systems, both of which exert excitatory and inhibitory influences on the sphincteric smooth muscle [29]. Yamato and Rattan [30] demonstrated that stimulation of $\alpha 1$-adrenoreceptors causes an increase in the resting pressure developed by the IAS. Multi-acting receptor targeted antipsychotics (MARTA) have a high affinity for a number of receptors including the dopaminergic D2, serotonergic 5-HT2A, $\alpha 1$-adrenergic, and muscarinic receptors. Two cases of FI have been reported in patients taking MARTA [31,32]. The pathophysiology is thought to be related to its central mechanism of action and inhibitory effects on the anal sphincters. Siproudhis et al. [33] reported that a single oral administration of 2 types of antidepressants (amitriptyline and fluoxetine) reduced pressure in the upper anal canal in 10 healthy male volunteers. Both drugs are likely to decrease the contractile activity of smooth muscle by inhibiting calcium channels.

Pelvic organ prolapse repair was also an independent risk factor for low MRP. Most studies reported a greater than $10 \%$ prevalence of FI in women with genital prolapse, and more than a third of women and men with rectal prolapse reported FI [34]. Internal rectal prolapse is a circular infolding of the rectal wall that occurs on straining to defecate. It descends into the rectum and may reach into the anal canal. Harmston et al. [35] found a significant reduction in MRP with progressive increases in the grade of internal rectal prolapse without a demonstrable effect on MSP. By contrast, external rectal prolapse was associated with a significant reduction in both MRP and MSP [36]. The underlying mechanism has been postulated to result from nerve damage by stretching due to perineal descent or sphincter dilatation and inappropriate stimulation of the recto-anal inhibitory reflex by the prolapsing rectum [37]. The finding of decreased MRP without a significant change in MSP suggests that the predominant effect of internal rectal prolapse is on reducing IAS tone without an effect on EAS.

\section{CONCLUSION}

IASD has received little attention, and the results of this study indicate that it is a major problem for elderly people in Japan. In addition, the importance of IASD as a public health problem is likely to increase in the near future as the elderly population continues to grow. This cross-sectional study offers evidence that IASD is correlated with the presence of certain conditions such as age, sex, FI, mental disease, and pelvic organ prolapse. Several of these risk factors for IASD are potentially preventable or modifiable; for example, several studies have shown a recovery in MRP after rectal prolapse repair [35]. Improving our understanding of risk factors, particularly modifiable risk factors, is critical for developing future prevention guidelines and improving the specificity of FI treatment.

\section{REFERENCES}

[1] Madoff, R.D., Parker, S.C., Varma, M.G., et al. (2004) Faecal incontinence in adults. Lancet, 364, 621-632. doi:10.1016/S0140-6736(04)16856-6

[2] Rao, S.S.C. (2004) Diagnosis and management of fecal incontinence. American Journal of Gastroenterology, 99, 1585-1604. doi:10.1111/j.1572-0241.2004.40105.x

[3] Frenckner, B. and Euler, C.V. (1975) Influence of pudendal block on the function of the anal sphincters. Gut, 16, 482-489. doi:10.1136/gut.16.6.482

[4] Barnett, J.L., Hasler, W.L. and Camilleri, M. (1999) American gastroenterological association medical position statement on anorectal testing techniques. Gastroenterology, 116, 732-760.

doi:10.1016/S0016-5085(99)70194-0

[5] Bordeianou, L., Lee, K.Y., Rockwood, T., et al. (2008) Anal resting pressures at manometry correlate with the fecal incontinence severity index and with presence of sphincter defects on ultrasound. Disease of Colon and Rectum, 51, 1010-1014. doi:10.1007/s10350-008-9230-7

[6] Varma, M.G., Brown, J.S., Creasman, J.M., et al. (2006) Fecal incontinence in females older than aged 40 years: Who is at risk? Disease of Colon and Rectum, 49, 841851. doi:10.1007/s10350-006-0535-0

[7] Whitehead, W.E., Borrud, L., Goode, P.S., et al. (2009) Fecal incontinence in US adults: Epidemiology and risk factors. Gastroenterology, 137, 512-517.

doi:10.1053/j.gastro.2009.04.054

[8] Joh, H.K., Seong, M.K. and Oh, S.W. (2010) Fecal incontinence in elderly Koreans. Journal of the American Geriatrics Society, 58, 116-121. doi:10.1111/j.1532-5415.2009.02613.x

[9] Lewis, S.J. and Heaton, K.W. (1997) Stool form scale as a useful guide to intestinal transit time. Scandinavian Journal of Gastroenterology, 32, 920-924. doi:10.3109/00365529709011203

[10] Rao, S.S. and Patel, R.S. (1997) How useful are manometric tests of anorectal function in the management of 
defecation disorders? American Journal of Gastroenterology, 92, 469-475.

[11] Abe, T., Kunimoto, M. and Hachiro, Y. (2008) Diagnosis and management of fecal incontinence at a specialty outpatient clinic. Journal of Japan Society of Coloproctology, 61, 247-253. doi:10.3862/jcoloproctology.61.247

[12] Laurberg, S. and Swash, M. (1989) Effects of aging on the anorectal sphincters and their innervation. Disease of Colon and Rectum, 32, 737-742. doi:10.1007/BF02562120

[13] Enck, P., Kuhlbusch, R., Lübke, H., et al. (1989) Age and sex and anorectal manometry in incontinence. Disease of Colon and Rectum, 32, 1026-1030. doi:10.1007/BF02553874

[14] Rao, S.S., Hatfield, R., Soffer, E., et al. (1999) Manometric tests in anorectal function in healthy adults. American Journal of Gastroenterology, 94, 773-783. doi:10.1111/j.1572-0241.1999.00950.x

[15] Gundling, F., Seidl, H., Scalercio, N., et al. (2009) Influence of gender and age on anorectal function: Normal values from anorectal manometry in a large Caucasian population. Digestion, 81, 207-213. doi: $10.1159 / 000258662$

[16] Speakman, C.T.M., Hoyle, C.H.V., Kamm, M.A., et al. (1995) Abnormal internal anal sphincter fibrosis and elasticity in fecal incontinence. Disease of Colon and Rectum, 38, 407-410. doi:10.1007/BF02054231

[17] Abe, T., Sato, Y., Kunimoto, M., et al. (2008) Effect of aging and gender on internal anal sphincter thickness. Anti-Aging Medicine, 5, 46-48. doi:10.3793/jaam.5.46

[18] MacLennan, A.H., Taylor, A.W., Wilson, D.H., et al. (2000) The prevalence of pelvic floor disorders and their relationship to gender, age, parity and mode of delivery. British Journal of Obstetrics and Gynaecology, 107, 1460-1470. doi:10.1111/j.1471-0528.2000.tb11669.x

[19] Nelson, R., Norton, N., Cautley, E., et al. (1995) Community-based prevalence of anal incontinence. Journal of the American Medical Association, 274, 559-561. doi:10.1001/jama.274.7.559

[20] Bharucha, A.E., Zinsmeister, A.R., Locke, G.R., et al. (2006) Risk factors for fecal incontinence: A populationbased study in women. American Journal of Gastroenterology, 101, 1305-1312. doi:10.1111/j.1572-0241.2006.00553.x

[21] Faltin, D.L., Boulvain, M., Irion, O., et al. (2000) Diagnosis of anal sphincter tears by postpartum endosonography to predict fecal incontinence. Obstetrics and Gynecology, 95, 643-647. doi:10.1016/S0029-7844(99)00631-6

[22] Burnett, S.J., Spence-Jones, C., Speakman, C.T., et al. (1991) Unsuspected sphincter damage following childbirth revealed by anal endosonography. British Journal of Radiology, 64, 225-227. doi:10.1259/0007-1285-64-759-225

[23] Ward, A. and Tunuguntla, A.K. (1984) Anorectal sensorimotor dysfunction in fecal incontinence and diabetes mellitus. New England Journal of Medicine, 310, 12821287. doi:10.1056/NEJM198405173102003
[24] Schiller, L.R., Santa Ana, C.A., Schmulen, C., et al. (1982) Pathogenesis of fecal incontinence in diabetes mellitus: Evidence for internal anal sphincter dysfunction. New England Journal of Medicine, 307, 1666-1671. doi:10.1056/NEJM198212303072702

[25] Rogers, J., Levy, D.M., Henry, M.M., et al. (1988) Pelvic floor neuropathy: A comparative study of diabetes mellitus and idiopathic faecal incontinence. Gut, 29, 756-761. doi:10.1136/gut.29.6.756

[26] Pintor, M.P., Zara, G.P., Falletto, E., et al. (1994) Pudendal neuropathy in diabetic patients with faecal incontinence. International Journal of Colorectal Disease, 9, 105-109. doi:10.1007/BF00699423

[27] Erckenbrecht, J.F., Winter, H.J., Cicmir, I., et al. (1988) Faecal incontinence in diabetes mellitus: Is it correlated to diabetic autonomic or peripheral neuropathy? Zeitschrift fur Gastroenterologie, 26, 731-736.

[28] Watanabe, M., Tsunoda, A., Kamiyama, G., et al. (2003) Pathophysiology in diabetic patients with fecal incontinence. Showa University Journal of Medical Sciences, 15, 21-26.

[29] Mills, K. and Chess-Williams, R. (2009) Pharmacology of the internal anal sphincter and its relevance to faecal incontinence. Autonomic and Autacoid Pharmacology, 29, 85-95. doi:10.1111/j.1474-8673.2009.00437.x

[30] Yamato, S. and Rattan, S. (1990) Role of alpha adrenoceptors in opossum internal anal sphincter. Journal of Clinical Investigation, 86, 424-429. doi:10.1172/JCI114728

[31] Mendhekar, D.N., Srivastav, P.K., Sarin, S.K., et al. (2003) A case report of olanzapine-induced fecal incontinence. Journal of Clinical Psychiatry, 61, 601-602.

[32] Sagar, R., Varghese, S.T. and Balhara, Y.P. (2005) Olanzapine-induced double incontinesnce. Indian Journal of Medical Sciences, 59, 163-164. doi:10.4103/0019-5359.16123

[33] Siproudhis, L., Dinasquet, M., Sébille, V., et al. (2004) Differential effects of two types of antidepressants, amitrptyline and fluoxetine, on anorectal motility and visceral perception. Alimentary Pharmacology and Therapeutics, 20, 689-695. doi:10.1111/j.1365-2036.2004.02151.x

[34] Shamliyan, T., Wyman, J., Bliss, D.Z., et al. (2007) Prevention of urinary and fecal incontinence in adults. Evidence Reports/Technology Assessments, 161, 1-379.

[35] Harmston, C., Jones, O.M., Cunningham, C., et al. (2011) The relationship between internal rectal prolapse and internal anal sphincter function. Colorectal Disease, 13, 791-795. doi:10.1111/j.1463-1318.2010.02266.x

[36] Hiltunen, K.M., Matikainen, M., Auvinen, O., et al. (1986) Clinical and manometric evaluation of anal sphincter function in patients with rectal prolapse. American Journal of Surgery, 151, 489-492. doi:10.1016/0002-9610(86)90110-8

[37] Furouk, R., Duthie, G.S., MacGregor, A.B., et al. (1994) Recto-anal inhibition and incontinence in patients with rectal prolapse. British Journal of Surgery, 81, 743-746. doi:10.1002/bjs. 1800810542 